\title{
Breves análises da Educação Superior Brasileira na modalidade EaD
}

\author{
FLORÊNCIO, Roberto Remígio ${ }^{1}$ \\ OLIVEIRA, Ana Cristina Barbosa de ${ }^{2}$
}

\section{RESUMO}

O presente manuscrito apresenta um estudo sobre o Ensino Superior no Brasil na modalidade EaD, analisando mecanismos e instrumentos de avaliação de algumas IES como elementos de promoção de competências e habilidades para o exercício profissional. A pesquisa ocorreu durante os meses de outubro de 2018 a março de 2019, a partir de levantamento de dados, revisão bibliográfica e análise documental, através dos portais das principais instituições promotoras de cursos de graduação on-line. A metodologia de análise de dados está baseada na Análise de Conteúdo. Os resultados alcançados formam um grande apanhado de informações sobre a EaD no Brasil como nicho mercadológico, possibilidades de inovação pedagógica e fomentadora de discussões, interação e colaboração entre participantes dos Ambientes Virtuais de Aprendizagem. Como conclusões, identificamos fissuras paradigmáticas da formação acadêmica e novas problemáticas acerca do papel da Educação Superior no Brasil contemporâneo, em sua constituição essencial: ensino, pesquisa, extensão e inovação.

\section{Educação a Distância. Ambiente Virtual de Aprendizagem. Tecnologia Educacional. Formação de Professores.}

\section{Fast analysis of Brazilian Higher Education in distance education}

\section{ABSTRACT}

The present manuscript presents a study on Higher Education in Brazil in the EaD modality, analyzing mechanisms and instruments of evaluation of some HEls as elements to promote competences and skills for professional practice. The research took place during the months of October 2018 to March 2019, based on data collection, bibliographic review and document analysis, through the portals of the main institutions promoting online undergraduate courses. The

\footnotetext{
1 Doutorando em Educação (UFBA). Mestre em Educação e Cultura e Territórios Semiáridos (UNEB). Especialista em Educação (UNEB) e em Língua Portuguesa (UNIVERSO). Licenciado em Letras (UPE) e em Pedagogia (UNEB). Professor efetivo do IF Sertão Pernambucano. Email: betoremigio@yahoo.com.br. Lattes: http://lattes.cnpq.br/2827979747157274. Orcid: https://orcid.org/0000-0003-3590-9022.

2 Mestra em Ecologia Humana e Gestão Socioambiental (UNEB). Bacharela em Engenharia Florestal (UFPB). Especialista em Psicopedagogia (UPE). Graduada em Ciências Biológicas (UNIVASF). Professora visitante da Universidade do Estado da Bahia (UNEB). E-mail: chrisbarbosa_2@hotmail.com. Lattes: http://lattes.cnpq.br/6351956609063706. Orcid: https://orcid.org/0000-0002-2225-818X.
}

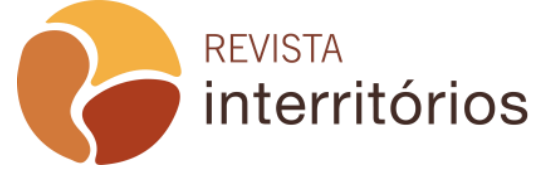

Interritórios | Revista de Educação Universidade Federal de Pernambuco, Caruaru, BRASIL | V.6 N.11 [2020] 
data analysis methodology is based on Content Analysis. The results achieved form a great collection of information about Distance Education in Brazil as a market niche, possibilities for pedagogical innovation and foster discussions, interaction and collaboration between participants in the Virtual Learning Environments. As conclusions, we identified paradigmatic fissures in academic education and new problems regarding the role of Higher Education in contemporary Brazil, in its essential constitution: teaching, research, extension and innovation.

Distance Education. Virtual learning environment. Educational technology. Teacher training.

\section{Breve Análisis de la Educación Superior Brasileña en la Modalidad de Educación a Distancia}

\section{RESUMEN}

El presente manuscrito presenta un estudio sobre Educación Superior en Brasil en la modalidad de Educación a Distancia, analizando mecanismos e instrumentos para la evaluación de algunas IES como elementos para promover competencias y habilidades para la práctica profesional. La investigación se llevó a cabo durante los meses de octubre de 2018 a marzo de 2019, basada en la recopilación de datos, la revisión bibliográfica y el análisis de documentos, a través de los portales de las principales instituciones que promueven cursos de pregrado on-line. La metodología de análisis de datos se basa en el análisis de contenido. Los resultados obtenidos forman una gran colección de informaciones sobre la educación a distancia en Brasil como un nicho de mercado, posibilidades de innovación pedagógica y fomento de debates, interacción y colaboración entre los participantes en los ambientes virtuales de aprendizaje. Como conclusiones, identificamos fisuras paradigmáticas en la educación académica y nuevos problemas con respecto al papel de la Educación Superior en el Brasil contemporáneo, en su constitución esencial: enseñanza, investigación, extensión e innovación.

\section{Educación a distancia. Ambiente de Aprendizaje Virtual. Tecnología Educacional. Formación de Profesores.}

\section{Breve analisi dell'istruzione superiore brasiliana nell'istruzione a distanza}

\section{RIASSUNTO}

II presente manoscritto presenta uno studio sull'istruzione superiore in Brasile nella modalità di istruzione a distanza, analizzando i meccanismi e gli strumenti per la valutazione di alcuni istituti di istruzione superiore come elementi per promuovere le competenze e le abilità per la pratica professionale. La ricerca si è svolta nei mesi da ottobre 2018 a marzo 2019, sulla base della raccolta dei dati,

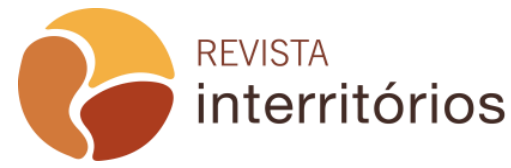


della revisione bibliografica e dell'analisi dei documenti, attraverso i portali delle principali istituzioni che promuovono corsi universitari online. La metodologia di analisi dei dati si basa sull'analisi dei contenuti. I risultati ottenuti formano una grande raccolta di informazioni sull'istruzione a distanza in Brasile come nicchia di mercato, possibilità di innovazione pedagogica e promozione di discussioni, interazione e collaborazione tra i partecipanti negli ambienti di apprendimento virtuale. Come conclusioni, abbiamo identificato ragadi paradigmatiche nell'istruzione accademica e nuovi problemi riguardanti il ruolo dell'istruzione superiore nel Brasile contemporaneo, nella sua costituzione essenziale: insegnamento, ricerca, estensione e innovazione.

Formazione a distanza. Ambiente di apprendimento virtuale. Tecnologia educativa. Formazione degli insegnanti.

\section{INTRODUÇÃO}

Ainda que tenha ocorrido um grande avanço na democratização do Ensino Superior no Brasil nos últimos dez anos, o país ainda possui um índice percentual baixo em relação ao número de habitantes com curso superior completo (11\%, segundo IBGE, 2010; 2018). Em números totais, o país avançou pouco em relação à educação, ocupando a oitava posição entre os dez países que totalizam $72 \%$ da população mundial de adultos analfabetos, estando atrás da Índia, China, Paquistão, Bangladesh, Nigéria, Etiópia e Egito (UNESCO, $2014 ; 2017)$. Estes, entre outros aspectos, tornam o país um celeiro para o desenvolvimento de práticas pedagógicas via internet. Por isso, é importante que pesquisas sobre essa temática provoquem a agenda sobre o ensino no Brasil, mais especificamente sobre a Educação a Distância (EaD). E, para os estudantes dessa modalidade, além de uma visão metalinguística do assunto, é a própria segurança de se conhecer profundamente a regulamentação que the confere legalidade, os mecanismos didático-pedagógicos que norteiam suas práticas e o conhecimento científico, aliado ao empírico do modus operandi dos portais virtuais, Ambiente Virtuais de Aprendizagem (AVA) e suas ferramentas e métodos de ensino-aprendizagem e avaliação.

A relevância social desta modalidade de ensino está relacionada ao complexo contexto nacional, levando em considerações fatores sociais brasileiros largamente (re)conhecidos, em que grande parte da população apresenta dificuldades de ingressar no ensino superior e os motivos mais comuns são: número de vagas insuficiente nas instituições públicas; preços elevados das instituições particulares presenciais; impossibilidade de trabalhar e estudar concomitantemente. Enquanto que, na EaD, os horários de estudo são flexíveis, levando em consideração a rotina dos estudantes, pela possibilidade de estudar em qualquer lugar ou em qualquer momento, com acesso à internet. Segundo a UNIVERSIA (2016), instituição que reúne diversas instituições de

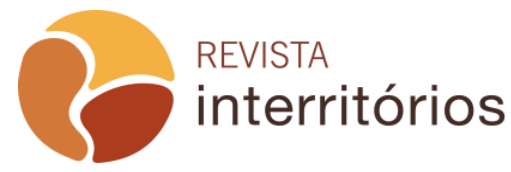


ensino on-line, o acesso dificultado aos espaços físicos, devido a problemas de mobilidade urbana/rural e a necessidade de formação e de certificação para acesso ao mercado de trabalho de forma mais célere, são as principais causas do aumento exponencial dos cursos superiores em EaD.

No entanto, as dúvidas sobre o atual sistema dessa modalidade estão relacionadas à qualidade do ensino e do sistema de avaliação: a aprendizagem no ensino EaD é realmente efetiva ou serve apenas para a complementação do currículo? Por isso, tornou-se necessário analisar os principais portais de Educação a Distância de Instituições de Ensino Superior (IES), os principais Ambientes Virtuais de Aprendizagem (AVA), dando ênfase ao Moodle; além de efetivar um levantamento acerca das IES, analisando os seus sistemas de ensino, sua interação com as TIC e a responsabilidade social que o expediente demanda para a sociedade, observando mecanismos dessa modalidade de ensino como elemento de promoção de competências e habilidades para 0 exercício profissional.

Trata-se de uma pesquisa de cunho qualitativo e quantitativo, realizada através de levantamento bibliográfico, que evidencia uma análise de dados a partir de publicações sobre a temática, a fim de se compreender a interação entre as TIC e o ambiente EaD, como também apresentar os resultados obtidos através dos estudos levantados na base de dados propostos pela Análise de Conteúdo, embasado por Bardin (2009), Demo (2009), Moran (2002), Lucena (1998), Azevedo (2000), Miranda (2005), Lemgruber (s/d) e Kensky (2015).

\section{Referencial teórico e contextual da EAD no Brasil}

Os primeiros registros da EaD no Brasil, datados de 1904 (ALVES, 2011), se caracterizavam por cursos de áreas técnicas por correspondência e, por volta de 1923, são ofertados cursos de Português, Francês, Silvicultura, Literatura Francesa, Esperanto, Radiotelegrafia e Telefonia, dando início a Educação a Distância pelo rádio. Posteriormente em 1974 - "surge o Instituto Padre Reus e na TV Ceará começam os cursos das antigas $5^{\underline{a}}$ à $8^{\text {a }}$ séries (atuais $6^{\circ}$ ao $9^{\circ}$ ano do Ensino Fundamental), com material televisivo, impresso e monitores" (ALVES, 2011, p. 88). Na segunda geração da EaD, marcada pela ascensão do rádio e da televisão dos anos 70 , Lemgruber ( $\mathrm{s} / \mathrm{d}$ ) afirma que o material impresso ainda é o principal suporte da modalidade á distância, e que a utilização da televisão, fitas de áudio, vídeo e o telefone passaram a crescer nesse período. $E$ no final do século $X X$, surge a internet que proporcionou abrangência geográfica de alunos e ferramentas tecnológicas que auxiliam as práticas de ensino.

Em 20 de dezembro de 1996 foi sancionada a Lei № 9.394/96 (Lei de Diretrizes e Bases da Educação - LDB), em especial o artigo 80, institui que o

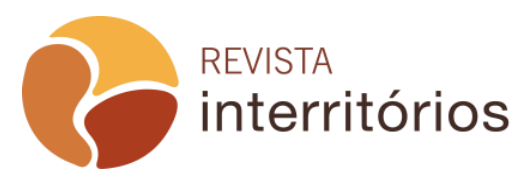


governo promoverá políticas de incentivo à modalidade de ensino à distância em todos os níveis (BRASIL, 1996). Neste mesmo artigo, determina-se que o Plano Nacional de Educação (PNE) seja executado, entrando em vigor com a Lei 10.172/01, em janeiro de 2001. Um dos seus capítulos diz que o "ensino à distância é auxiliar e eficaz para combater os déficits educativos e as desigualdades regionais" (BRASIL, 2001). Porém, o desenvolvimento da EaD no Brasil só se efetivou com o Decreto № 5.622, de 19 de dezembro de 2005 (BRASIL, 2005), que reconheceu os cursos oferecidos pelas instituições credenciadas pelo MEC nesta modalidade. Depois, leis foram promulgadas e outras revogadas com o intuito de regulamentar a oferta e qualidade de cursos, com os objetivos de afirmar a sua credibilidade e o seu potencial enquanto ensino-aprendizagem, antes tratada como uma educação marginalizada e uma segunda opção para pessoas sem acesso à educação presencial. Naquele ano, o poder público criou a Universidade Aberta do Brasil (UAB), e várias universidades públicas e centros tecnológicos se uniram para formar associações para disponibilizar cursos a distância, dando origem aos polos.

Polos de educação a distância, entendidos como unidades operativas, no País e no exterior, que poderão ser organizados em conjunto com outras instituições, para a execução descentralizada de funções pedagógico-administrativas do curso, quando for o caso. Definição do Decreto 5.622/2005. (BRASIL, 2005).

Foi disposto na LEI № 13.005, de 25 de junho de 2014 que na Meta 12 do PNE, a ser cumprida até 2024 , elevaria a taxa bruta de matrícula na educação superior para $50 \%$ e a taxa líquida para $33 \%$ da população de 18 a 24 anos. Azevedo (2000) salienta a proposta a EaD de aumentar a capacidade do sistema de ensino superior para atender a esta demanda, mas ao mesmo tempo isto deve ser feito sem o sacrifício da qualidade do ensino e da formação profissional. Em 20 de junho de 2017, foi estabelecida a Portaria Normativa № 11, com o intuito de ajudar a desburocratizar o credenciamento das instituições que ofertam EaD (BRASIL, 2017). Estas conquistas na EaD se devem aos teóricos Landim (1997), Niskier (2000), Nunes (1998), Belloni (1999), Valente (2000), Martins (2005), Neves e Cunha (2000) que vêm dando contribuições no estudo de interfaces, metodologias, interação e colaboração, conforme Mugnol (2009), entre outros autores mais recentes ligados ao estudo das teorias pedagógicas EaD (MAIA, 2016) estão, Almeida (2003), Rodrigues (2011), Alves (2011), Anderson e Dron (2012), Mattar (2013).

\section{Janelas para o conhecimento}


De frente a um notebook, computador, celular ou qualquer dispositivo eletrônico, a tela permite a visualização de textos, imagens, a busca por investigação, pesquisas que leve ao conhecimento, provocando uma comunicação visual com explanações do material de estudo e das atividades a desenvolver, inseridos no contexto EaD que de acordo com Kenski (2015, p. 133) frisa que "o ir à escola para se educar e aprender transforma-se em metáfora para a aprendizagem por diversas formas e meios, inclusive os digitais".

A associação da tela do computador utilizada na transmissão de imagens com a necessidade de um espaço onde o docente pudesse visualizar e aplicar as práticas pedagógicas de forma mais realista resultaram no surgimento dos Ambientes Virtuais de Aprendizagem (AVA) ou Learning Management Systems (LMS - sistemas de gerenciamento de aprendizagem), que são softwares educacionais providos de tecnologias de informação e comunicação, com capacidade de armazenar e atender uma maior demanda de estudantes, distribuir e ser acessado através de qualquer dispositivo eletrônico com internet. Os AVAs representam um conjunto de ferramentas eletrônicas capazes de "organizar conteúdos, acompanhar atividades e, fornecer ao estudante suporte on-line e comunicação eletrônica” (MCKIMM; JOLLIE; CANTILLON, 2003, apud PEREIRA; SCHMITTE; DIAS, 2007, p. 6) direcionada ao ensino-aprendizagem.

Existem diversas ferramentas tecnológicas classificadas em síncronas (quando a interação ocorre em tempo real) e assíncronas (quando o indivíduo não precisa estar online, ou seja, tempos diferentes), elas têm a função de executar a comunicação/interação. Dentre as ferramentas mais usuais podemos destacar:

- o chat (bate-papo): utilizado para discutir textos, ideias, situações e perguntas-problema, esclarecimento entre os alunos ou entre estes e o professor-tutor, normalmente com tempo determinado para a interação;

- o fórum de discussão: ferramenta de publicações de textos, espaço de questionamentos, argumentos e exposição de ideias que ficam "salvos para posterior uso e conferência" (DEMO, 2009, p. 47), além de meio para avaliações;

- o e-mail: segundo Miranda (2005), é um sistema de correio eletrônico com envio, recebimento de arquivos anexados, correspondência para 0 endereço eletrônico, que pode ser direcionado de uma pessoa para outra ou de um indivíduo para um grupo com o auxílio da web, essa abrangência e facilidade na comunicação o torna uma ferramenta assíncrona muito usada nos cursos online.

- Wiki, em havaiano significa "rápido" (TONKE apud COUTINHO; BOTTENTUIT JUNIOR, 2007), a sua estrutura lógica é muito semelhante à de um blog, mas com a funcionalidade acrescida de que qualquer um pode juntar, editar e apagar conteúdos ainda que estes tenham sido criados por outros autores. 


\section{O teclado: interação e inserção de dados nas plataformas}

Conjunto de teclas que proporciona execução dos comandos na navegação, digitação, edição de textos em dispositivos eletrônicos. Através do teclado o estudante EaD se comunica com trocas de informações, levantamento de dúvidas, perguntas, problematizações, discussões, metáfora, interagindo com os membros do curso nas publicações de suas atividades. Segundo Landin (1997, p. 47),

um método de conversação didática guiada em que o sistema a distância implica estudar por si mesmo, mas o aluno não está só, vale-se de um curso e de interação com instrutores e com uma organização de apoio que executa um diálogo no movimento duplo.

\section{A conexão: ligação entre ensino e aprendizagem}

Em uma simples deslocação corpórea, com a movimentação da mão a fim de ligar o aparelho tecnológico e em seguida, conectando-o à internet, 0 aluno se vê conectado ao curso pretendido, tendo a oportunidade de avançar por conteúdos, artigos e textos que lhes despertem o interesse, sem haver a necessidade do deslocamento ao espaço físico da instituição ou biblioteca. Kensky (2015, p. 16) argumenta que:
A facilidade de acesso à informação lhes garante condições para orientar suas próprias trilhas de aprendizagem, de acordo com seus interesses e necessidades e a participação em cursos online livres, com temas diversificados, Ihes possibilita uma formação em concordância com suas prioridades.

A mediação pedagógica na EaD é constituída por uma equipe de profissionais capacitados, com o objetivo de promover engajamento, interação, sanar dúvidas e facilitar o conhecimento dos discentes. Sendo assim, esta envolve o professor, o tutor presencial e o tutor à distância. O professor é o responsável teoricamente para a ministração da disciplina de sua responsabilidade, selecionar materiais e teóricos, definir as atividades pedagógicas, colocar o estudante em contato com o seu objeto de estudo, contribuindo para o processo de ensino e aprendizagem (MOTTA; GAVILON, 2010).

O tutor presencial é a pessoa que integra o espaço físico, estando presente no polo de apoio com horários e dias definidos. Tem por objetivo

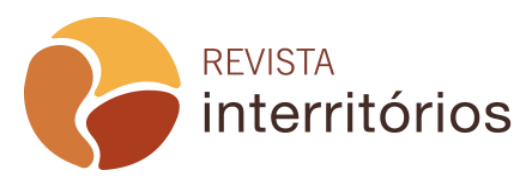

Interritórios | Revista de Educação

Universidade Federal de Pernambuco, Caruaru, BRASIL | V.6 N.11 [2020] 
(MORAN, 2009, p. 27) "tirar dúvidas, participar das atividades solicitadas e dos laboratórios de informática e outros, específicos do curso". Ainda, para que a mediação ocorra de maneira satisfatória, existe o tutor a distância, que mesmo distante espacialmente o contato entre o discente e o docente é mediado por tecnologias (MORAN, 2002).

\section{Procedimentos metodológicos}

A abordagem metodológica da pesquisa, de natureza quali-quantitativa, constitui-se de análise documental e revisão de literatura, a partir de um levantamento de dados a partir das palavras-chave: Ensino Superior a Distância e Ambientes Virtuais de Aprendizagem. O levantamento bibliográfico, do período de 1996 a 2019, foi pesquisado entre os meses de novembro/18 e março/19 selecionando teses de doutorado, dissertações de mestrado e artigos publicados em periódicos, consultados nas principais bases de dados de acesso à pesquisa Scielo, Google Acadêmico, além de legislação pertinente e documentos oficiais do Ministério da Educação. O material selecionado foi analisado separadamente com base na Análise de Conteúdo (AC), de Bardin (2009), que se preocupa com as seguintes questões: a organização da análise, a codificação de resultados, as categorizações, as inferências e, por fim, a informatização da análise das comunicações.

Para uma aplicabilidade coerente do método, de acordo com os pressupostos de uma interpretação das mensagens e dos enunciados, a AC deve ter como ponto de partida uma organização. As diferentes fases da AC organizam-se em torno de três etapas, conforme Bardin (2009, p. 121): 1. A préanálise; 2. A exploração do material e 3. O tratamento dos resultados: a inferência e a interpretação. E, na seleção dos assuntos durante a pesquisa, adotou-se como critério de inclusão do material pesquisado as ideias centrais que representam o foco desta análise, visualizado nas concepções e representações do título, resumo e palavras-chave.

A pré-análise, primeira fase desta organização de AC objetiva a sistematização para que o pesquisador possa conduzir as operações sucessivas de análise. Assim, num plano inicial, a missão desta primeira fase corresponde a etapa de organização do material a ser utilizado com o objetivo de torná-lo operacional, sistematizando as ideias iniciais. Trata-se da organização propriamente dita por meio de quatro etapas: a) leitura flutuante, que é o estabelecimento de contato com os documentos da coleta de dados, momento em que se começa a conhecer o texto; b) escolha dos documentos, que consiste na demarcação do que será analisado; c) formulação das hipóteses e objetivos; d) referenciação dos índices e elaboração de indicadores, que envolve a determinação de indicadores por meio de recortes de texto nos documentos de 
análise (BARDIN, 2009), as demais etapas, consiste a codificação e a categorização que nada mais é do que selecionar as ideias semelhantes e as diferentes, reagrupando com a finalidade de obter características comuns. Então, como partimos de um "universo de documentos de análise" (Ibid., p. 122), trata-se, portanto, de reconhecer que para um trabalho mais produtivo de AC é necessário restringir as amostragens. "A amostragem diz-se rigorosa se a amostra for parte representativa do universo inicial" (Ibid., p. 123). Nesse sentido, Bardin afirma que "nem todo o material de análise é susceptível de dar lugar a uma amostragem, e, nesse caso, mais vale abstermo-nos e reduzir o próprio universo (e, portanto, o alcance da análise) se este for demasiado importante" (lbid., p. 123).

A segunda fase, que consiste na exploração do material com a definição de categorias e a identificação das unidades de registro e das unidades de contexto nos documentos. A exploração do material consiste numa etapa importante, porque vai possibilitar ou não a riqueza das interpretações e inferências. Esta é a fase da descrição analítica, a qual diz respeito ao corpus (qualquer material textual coletado) submetido a um estudo aprofundado, orientado pelas hipóteses e referenciais teóricos. Dessa forma, a codificação, a classificação e a categorização são básicas nesta fase (Id., 2006). Importante salientar para o que (ld., 2010, p. 121) chama atenção nessa fase:

$\mathrm{Na}$ fase de exploração do material, ocorre a aplicação sistemática, manual ou informatizada, das decisões tomadas na pré-análise. Consiste, essencialmente em operações de codificação, decomposição ou enumeração, em função das regras previamente estabelecidas.

A terceira fase diz respeito ao tratamento dos resultados, inferência e interpretação. Esta etapa é destinada ao tratamento dos resultados; ocorre nela a condensação e o destaque das informações para análise, culminando nas interpretações inferenciais; é o momento da intuição, da análise reflexiva e crítica (ld., 2009). Dos 40 artigos trabalhados, 15 foram com base nas pesquisas realizadas no Scientific Eletronic Library Online (SciELO), que possibilitou numa representativa maior entre as outras fontes pelo rigor e confiabilidade que esse site apresenta no meio acadêmico.

\section{Resultados e discussão}

A EaD ultrapassa os limites impostos pela educação tradicional na esfera espaço-tempo, capacita pessoas em diferentes locais e atinge, cada vez mais, maior número de adeptos. Uma única instituição educacional a distância pode ter vários polos de ensino espalhados pelo país. Moran (2009, p. 21) afirma que 
a EaD torna-se cada vez mais complexa, porque "está crescendo em todos os campos: com modelos diferentes, rápida evolução das redes, mobilidade tecnológica e abrangência dos sistemas de comunicação digitais".

Segundo a pesquisa do INEP, no Censo da Educação Superior de 2016, "são mais de 1,4 milhão de alunos estudando nos cursos EAD, o que representa uma participação de $18,6 \%$ dos alunos de graduação no país". Os motivos para essa expansão são diversos, sendo os principais o Decreto № 5.622 , de 2005, que reconhece a $\mathrm{EaD}$ como uma modalidade de ensino, e sua consequente regulação pelo MEC em 2006. Para Sathler, entre os benefícios oferecidos por esta modalidade estão as mensalidades mais acessíveis, os horários flexíveis e a possibilidade de estudar em qualquer lugar. "Temos um público adulto muito grande, já que a população brasileira está envelhecendo, e eles, geralmente, preferem a EaD, pois permite flexibilidade de tempo e ritmo de estudos" (UNIVERSIA, 2016, p.12).

\section{Gráfico 1: Número de matrículas em cursos de graduação por modalidade de ensino Brasil 2006 - 2016}

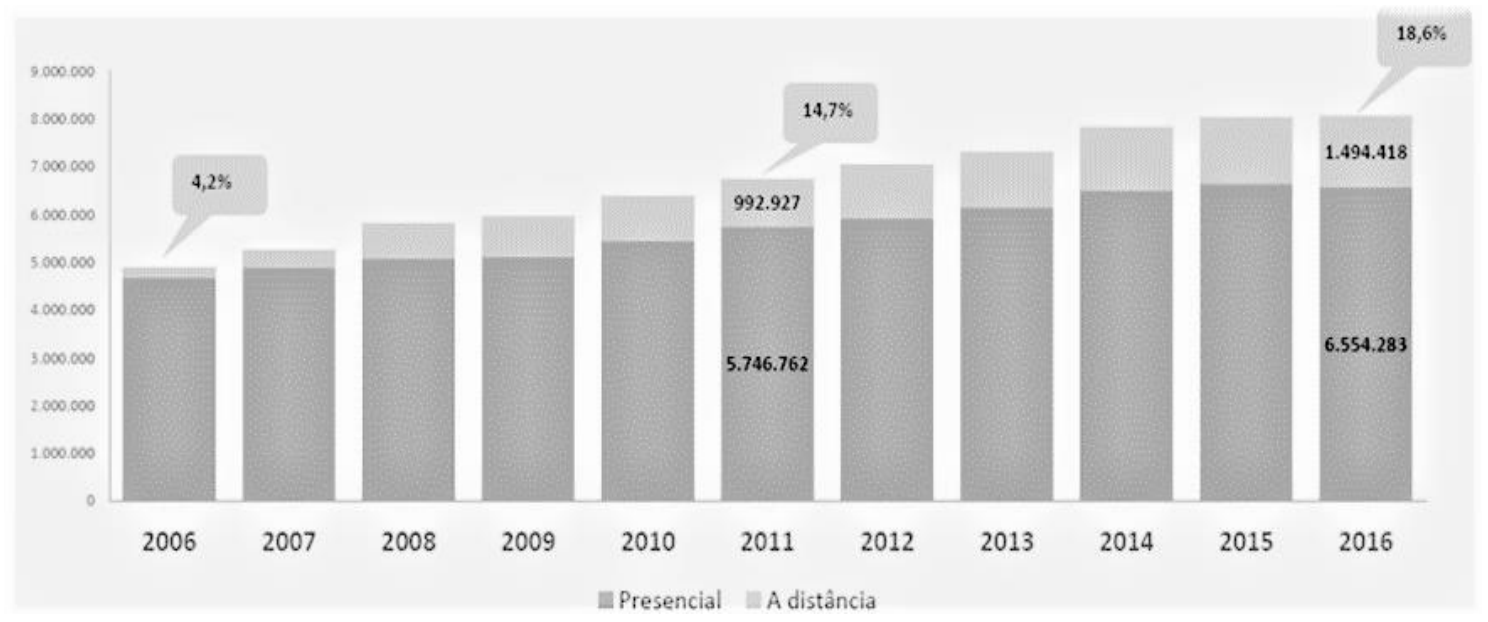

Fonte: MEC/INEP, 2016, p.21.

De acordo Pereira e Souza (2017, p. 4):

Ainda que matrículas em cursos de EaD não representem a maioria das matrículas de cursos de graduação no país, em termos absolutos, a tendência é de que, nos próximos anos permanecendo o crescimento exponencial constatado -, a predominância seja de matrículas em cursos de graduação na modalidade de EaD.

Pensando assim, gestores educacionais, em parceria com o Ministério da Educação, estão empenhados em promover mudanças no ensino superior EAD, e em especial o Governo Federal, em atingir suas metas (elevar o índice de pessoas com Ensino Superior, uma vez que esse percentual no Brasil ainda é

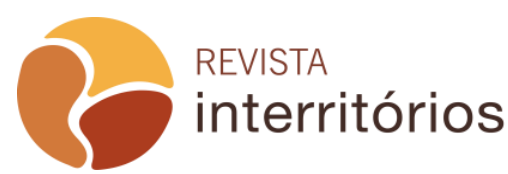


muito baixo em relação aos países como Chile, Argentina e outros da América Latina), como informa o último censo do MEC (BRASIL, 2016). Na modalidade EaD, é notório o crescimento de alunos nos últimos 10 anos, embora na rede pública, a representação dessa modalidade seja inferior em relação aos cursos de graduação presencial:

\section{Gráfico 2: Rede Federal - Distribuição da Matrícula em Cursos de Graduação}

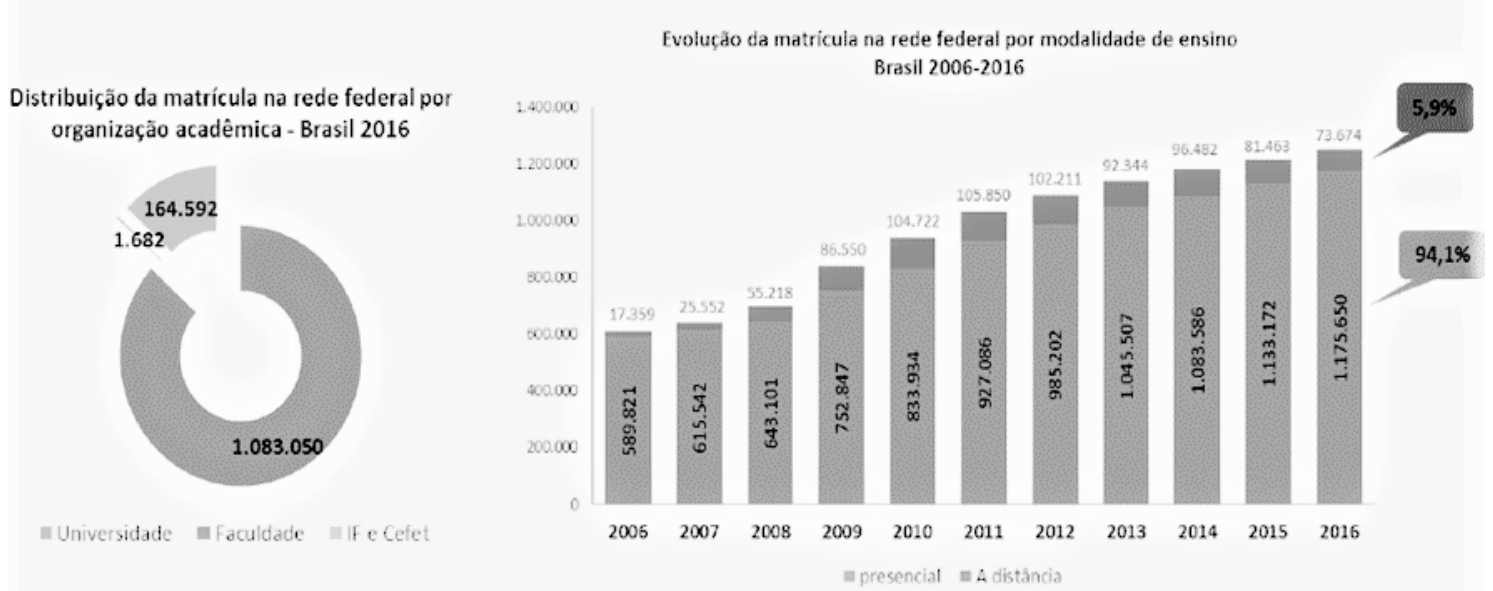

Fonte: MEC/INEP, 2016, p.35.

A democratização do acesso ao ensino superior foi estimulada por uma série de políticas públicas, no entanto, percebe-se que o avanço da EaD nas instituições públicas ainda é lento, conforme mostra a figura 2, com um percentual de 5,9\% se comparado ao presencial, que atinge $94,1 \%$ do número geral de matrículas. Segundo Belloni (2003, p. 15), "o campo da educação é extremamente complexo e altamente resistente à mudança".

Um dos aspectos que podemos relacionar com a expansão dos números de matrículas no ensino presencial em relação ao à distância se deve a implantação do Programa de Apoio a Planos de Reestruturação e Expansão das Universidades Federais - REUNI, instituído pelo Decreto $\mathrm{n}^{\circ}$ 6.096, de 24 de abril de 2007 (BRASIL, 2007). O REUNI permitiu o ingresso de mais estudantes presenciais nas instituições federais, com menor renda familiar, uma política de assistência estudantil que garantisse a permanência, à interiorização das IFES, vagas em cursos noturnos, ampliação da mobilidade estudantil, o programa possibilitou várias condições para realizar a expansão das IFES, apesar da precarização, com recursos insuficientes. "O Programa tem como meta global a elevação gradual da taxa de conclusão média dos cursos de graduação presenciais para 90\%" (BRASIL, 2007).

Em um país continental como o Brasil, repleto de desigualdades sociais, por questões político-administrativas e de territorialidade, a modalidade EaD, 
através de uma plataforma democrática de ensino, traz a praticidade, economicidade e a inclusão. Segundo Belloni (2008), a modalidade melhora a qualidade de ensino presencial e representa conquistas à população distante de instituições de ensino. Este gênero instrutivo oportuniza conhecimento, cultura e formação em diversas localidades brasileiras contribuindo para melhorar o nível de competência, instrução e habilidade das pessoas. Considerando que vivemos em uma sociedade neoliberal e globalizada, a EaD seria a tendência definida para atender as incitações político-econômico-sociais, na contemporaneidade das novas TIC.

Um dos aspectos analisados nessa pesquisa foi o percentual de instituições EaD por regiões brasileiras, segundo o Censo (2016) realizado pela ABED. As regiões Sul e Sudeste concentram 64\% das instituições EaD no país como mostra o gráfico 3. A região Sudeste por ter uma maior concentração populacional, abriga o maior número de faculdades EaD (37\%) e lidera com quase o dobro de alunos do segundo colocado, região Sul (27\%). A região Nordeste, com 18\% das instituições, encontra-se em terceiro lugar devido à extensão territorial e às desigualdades econômicas e a região Centro-Oeste, com $11 \%$. A Região Norte, apesar de apresentar maior necessidade pela grande extensão territorial e difíceis condições de transportes, possui o menos número percentual de IES com EaD, embora os números sejam mais condizentes com a porcentagem populacional.

Gráfico 3: Percentual dos cursos EaD, segundo região - Brasil: 2016

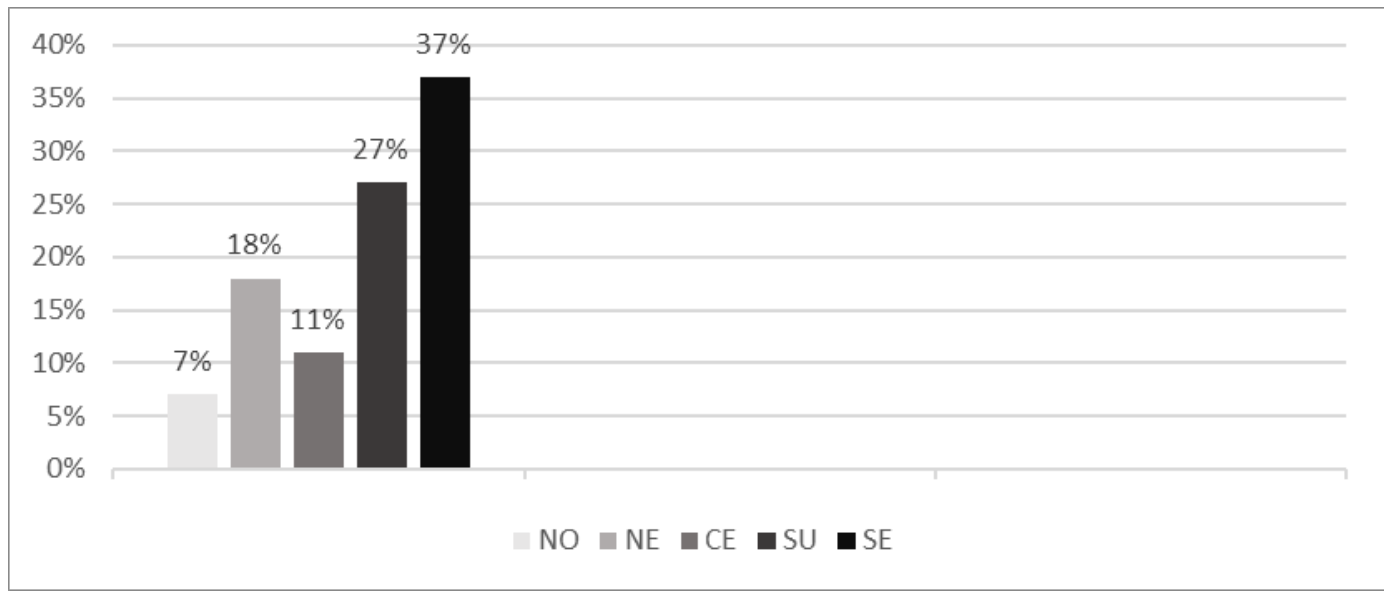

Fonte: MEC/INEP, 2016. Elaboração Própria.

A modalidade $\mathrm{EaD}$ fornece liberdade e flexibilidade no tempo e espaço, alternativa adequada ao mundo contemporâneo que vivenciamos, apesar da EaD requerer comprometimento disciplinar do aluno, ao realizar suas atividades e ter motivações para estudar, pois ele se enquadra como uma das principais figuras responsável pela sua aprendizagem, desenvolvendo um ritmo de estudo, fazendo um itinerário para realizar as atividades e avaliações, com

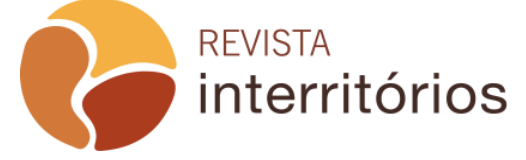


possibilidades de socialização (LITTO, 2004). Outro mito maniqueísta é a ideia segundo a qual a EaD é para 'todo mundo'. Pelo contrário, é sabido que um número substancial de aprendizes não tem a motivação, a autonomia e a disciplina necessárias para completar um curso universitário em EaD.

Com a expansão no acesso à internet e intranet, aumentaram as informações trocadas via web entre instituições, por isso surgiu os portais para otimizar essa demanda. O excesso de documentos armazenados nos computadores necessitava de solução para organizar todos os serviços prestados pelas instituições em um só ambiente via internet (TURBAN; KING, 2004). O portal mantém o excesso de informações em um ambiente virtual de fácil acesso, utilizando sistemas de buscas e classificação avançados. Os portais são considerados pelos autores como "portas de entrada" da informação e podem ser classificados em Portais de publicação, Portais comerciais, Portais pessoais, Portais corporativos, Portais de voz e Portais de afinidade (TURBAN; KING, 2004).

Os Portais Educacionais se diferenciam muito dos portais comerciais, na sua roupagem, devido à finalidade, ambos abusam de merchandising, porém, o portal de uma instituição de ensino a distância, tem que possibilitar o melhor acesso à informação e clareza na comunicação. Apesar disso, é fácil encontrar portais educacionais mistos, com características comerciais, pois as instituições privadas utilizam bastante da publicidade para atrair os estudantes.

No portal do MEC, é possível encontrar todas as instituições de EaD credenciadas, ou seja, autorizadas e reconhecidas para desenvolverem suas atividades no Ensino Superior. As IES à distância no Brasil fazem uso de portais, apresentando homepages repletas de tecnologias informativas, que oferecem páginas de acesso a serviços oferecidos pelas instituições. Geralmente esse ambiente virtual é composto por ícones direcionados a acessos a oferta de cursos, e-mail, biblioteca, portal do aluno, downloads, plataforma de ensino, conteúdo da história institucional, acesso a outros sites, emendas, mensalidades, editais, inscrições entre diversos serviços. A página do portal deve disponibilizar com clareza as informações, facilitando as atividades a serem realizadas pelos usuários. Os portais são sites sofisticados que ajudam o usuário a encontrar a informação.

De acordo com Licheski e Fadel (2013), os portais públicos federais devem apresentar-se uniformes nos seus conteúdos e nas páginas virtuais como intuito de possibilitar facilidade e acesso à informação a todos que usufruírem, bem como facilitar a portabilidade e a democratização do processo. Já as instituições privadas possuem alguns desses links, mais investem mais na apresentação mercadológica, com cores chamativas, marketing de custos e benefícios, ofertas de vantagens, índice de qualidades dos cursos e quantidade de sua abrangência. 


\section{Análise dos ambientes virtuais de aprendizagem}

Com o crescimento do Ensino Superior ofertado por universidades à distância, fez-se necessário o aprimoramento e aperfeiçoamento de ferramentas que viabilizassem a conexão entre o conhecimento transmitido e $o$ alunado. $A$ conexão entre estes, ocorre por meio do AVA, que consiste em "espaço fecundo de significação onde ser humano e máquina interagem potencializando a construção de conhecimentos" (SANTOS, 2003, p. 2).

Entende-se que o AVA consiste em uma sala de aula virtual onde o aluno tem participação ativa, por meio do acesso ao conhecimento, seja por meio de uma vídeo aula, a participação em fóruns de discussão e atividades propostas, além de inúmeras outras atividades. Tudo ocorrendo em espaços temporais diferenciados, mas com o mesmo objetivo: gerar o aprendizado. Existem várias plataformas disponíveis com a finalidade de promover a concepção de ambientes de aprendizagem, entre elas, as mais utilizadas são: Colaborar, Univirtus, Studeo TelEduc, Moodle, Blackboard, AulaNet e WebCT, são recursos potencializadores usados na comunicação entre aluno, professor, tutor e instituição, através de textos, vídeos, imagens, hiperlinks que permitem compartilhamento de informações de dentro para fora e vice-versa do ambiente.

A respeito do AVA, Gonçalves (2016, p. 25) salienta que "permite a realização de processos de aprendizagem significativa, colaborativa e é onde as atividades dos conteúdos estão organizadas e disponibilizadas para os alunos", em contrapartida, Belloni (2009, apud GONÇALVES, 2016, p. 26) ressalta que os ambientes virtuais possuem limitações, como falhas técnicas, lentidão na incorporação e entrega de vídeo/som, inabilidade do aluno com internet/dispositivo ou recursos tecnológicos de baixo desempenho.

Os AVA, por si só, não garantem bom desempenho e qualidade no seu funcionamento, mas são mídias que fazem uso de ciberespaço com propagação de informações e propicia interação no processo educativo (PEREIRA; SCHMITTE; DIAS, 2007). Santos (2009, apud FORNARI, 2018, p. 161) argumenta que "o AVA apresenta-se como uma organização viva, em que seres humanos e objetos técnicos interagem num processo complexo que se autoorganiza na dinâmica dialógica de suas redes de conexões".

\section{Plataforma MOODLE}

A evolução tecnológica tem tido impactos enormes em todos os domínios e setores de atividade da sociedade incluindo, naturalmente, as instituições educacionais, tanto nos processos de ensino e aprendizagem, como na gestão 
escolar, consequência da importância e influência das tecnologias no mundo globalizado. Vários autores, entre eles Santos e Jorge (2013), defendem que a utilização das plataformas de gestão de aprendizagem constitui uma grande oportunidade e, simultaneamente, coloca grandes desafios à instituição escolar e a todos os seus intervenientes, nomeadamente aos professores. Nesta perspectiva, Garrison e Anderson (2005) citados por (SANTOS; JORGE, 2013) evidenciam a aprendizagem do futuro baseada em ambientes educativos que promovam, simultaneamente, a autoformação e a aprendizagem colaborativa. As tecnologias digitais abrem novas perspectivas e possibilidades à criação e desenvolvimento de cenários e ambientes de aprendizagem que promovem a construção do conhecimento de modo colaborativo e cooperativo, na busca de melhores resultados para a educação. Intensificada pela plataforma Moodle, um dos AVA de maior aceitação mundial.

Sua simplicidade de uso [MOODLE] e, ao mesmo tempo, sua grande flexibilidade operacional e de configuração, além de sua capacidade de apresentação em um ambiente construtivista o consagram em mais de 230 países em todo o mundo, um total de mais de 68.000 sites, sendo mais de 4.600 somente no Brasil (MOODLEMOOT, 2014) .

A plataforma Moodle, Modular Object-Oriented Dynamic Learning, é um software livre com proposta de ensino e aprendizagem, de aplicação livre e fácil, de trabalho colaborativo, criada pelo Australiano Martin Dougiamas, em 2001 que identificou uma lacuna no sistema de gestão de aprendizagem no âmbito de seu projeto de doutoramento (ALVES; GOMES, 2007; PIMENTEL, 2009), citados por Santos e Jorge (2013). É conhecido como um LMS (Learning Management System) e também nomeado como CMS (Course Management System) ou VLE (Virtual Learning Environment). Estas diferentes categorizações atribuídas ao Moodle destacam as suas principais características: sistema que permite a gestão das aprendizagens através da criação e gestão de cursos/disciplina num ambiente virtual (Ibid).

Segundo Souza,Soares (2010) A Moodle foi construída com o objetivo de dar suporte a uma abordagem social do ensino, permitindo aos professores usufruir deste recurso como uma ferramenta para a sua prática letiva

Pimentel, 2009, afirma que ela permite a criação de cursos online, páginas de disciplinas, grupos de trabalho e comunidades de aprendizagem, tendo como filosofia uma abordagem social construtivista da educação.

A plataforma de aprendizagem Moodle se tornou a mais popular no âmbito educacional devido sua funcionalidade e dinamismo entre educadores e comunidade de aprendizagem do mundo todo. Neste âmbito, Santos e Jorge

\footnotetext{
3 in https://tecnologiasintegradasaeducacao531396497.wordpress.com/2018/06/02/moodlepedagogico-e-descomplicado-para-professores/ 
(2013, p.02) afirmam que os professores "desempenham um papel fundamental e destes depende, em grande medida, o sucesso da implementação das plataformas de gestão de aprendizagem nas escolas e o seu aproveitamento pedagógico". Os professores têm autonomia de construir sua sala virtual, montar e editar suas atividades, aplicar questionários de avaliação e enquetes com seus alunos, coletar e revisar tarefas, acessar e registrar notas, conversar com os alunos em tempo real, entre outras, enfim, dispõe de uma variedade de ferramentas online, possível e fácil de compartilhar todo o material de estudo. Com uma filosofia baseada na liberdade, partilha, interação, colaboração e cooperação, a Moodle se enquadra em modelos pedagógicos intimamente relacionados com uma filosofia de escola que tem como objetivos democratizar o acesso ao saber, desenvolver a autonomia e a reflexão do indivíduo, as suas competências e a sua capacidade de organizar e defender um ponto de vista. (SANTOS; JORGE, 2013).

\section{Considerações Finais}

Este estudo permitiu uma análise de como a EaD das IES tem evoluído no Brasil e a importância dos recursos tecnológicos utilizados nos ambientes virtuais que impulsionam uma interação e cooperação entre todos os envolvidos no processo de ensino-aprendizagem. No ensino à distância, o computador é a ferramenta principal para o aluno, através da internet ele acessa o ambiente virtual, além de ser um elemento essencial de interação entre aluno e professor. Essa modalidade, cada vez mais presente na educação brasileira, vem alcançando grande número de pessoas, de diferentes classes sociais, regiões geográficas e faixas etárias, interessadas em realizar o sonho de cursar o ensino superior, aperfeiçoar os estudos ou incrementar o currículo.

As novas metodologias utilizadas no processo de ensino EaD proporcionam mudanças no comportamento de seus usuários, conforme foi analisado nesse estudo: quebra de pré-conceitos sobre a autonomia dos estudantes e as transformações sociais que a EaD pode promover, com uma maior inclusão ao Ensino Superior, tanto pelo poder de abrangência territorial, como pela comodidade de receber/executar a formação sem deslocamento, muitas vezes impossível para pessoas com limitações físicas e/ou econômicas e de locomoção. Ambas fissuras paradigmáticas podem viabilizar uma transformação no quadro geral do nível de formação do povo brasileiro.

Verificou-se que para se ter sucesso nesta modalidade, é necessário que os envolvidos no processo de ensino/aprendizagem tenham ciência dos seguintes aspectos: o aluno deve ter autonomia, determinação, disciplina, organização, planejamento das atividades acadêmicas, conhecimento básico da informática, além dos fatores de interação e colaboração. Isto acontece com a aplicabilidade das interfaces que propiciam um estreitamento nas relações 
interpessoais professor e aluno, no desenvolvimento das atividades, questionamentos, feedbacks e avaliações, somente serão possíveis através de planejamentos didático-pedagógicos elaborados com o auxílio de metodologias e práticas educativas específicas, destinadas àquele público alvo.

Outro fator importante observado nesse estudo foi a diferença que a EaD tem nas regiões do país. Regiões com um maior percentual populacional, e mais desenvolvidas economicamente, possuem um maior número de instituições $\mathrm{EaD}$, sendo elas as regiões Sul e Sudeste, em seguida da região Nordeste. Já as regiões Norte e Centro Oeste constam com um menor número de instituições EaD, apesar de necessitarem por serem mais extensas, percebendo que não há uma democratização na oferta de ensino a distância.

Conclui-se também que a Plataforma Moodle é destaque entre as demais, devido sua filosofia baseada na liberdade, partilha, interação, colaboração e cooperação, enquadrando-se em modelos pedagógicos democráticos, proporcionando o acesso ao saber, desenvolve a autonomia e disciplina nos agentes desse processo, alunos, professores e tutores, além de ser uma plataforma de hospedagem altamente escalável, pois oferece uma boa relação custo-benefício. O Moodle veio otimizar a comunicação e interação dos envolvidos no processo de aprendizagem, ele representa o espaço "sala de aula", composto com as principais ferramentas tecnológicas fórum, chat e wiki entre outras para o desenvolvimento das atividades, realizadas e avaliadas. Ele quebra o paradigma mecânico encontrado na educação tradicional que de acordo com Silva (2010, p.228) "o aluno não está mais reduzido a olhar, ouvir, copiar e prestar contas. Ele cria, modifica, constrói, aumenta e, assim, torna-se co-autor". O Moodle oferece todas essas possibilidades para trabalhar essas competências, através dos fóruns de discussões, diário de bordo, construção coletiva de textos, fórum de apresentação, feedback, oportunizando a construir o conhecimento através dos métodos e práticas pedagógicas planejadas para determinado grupo coletivo com a mesma finalidade de curso. Então, pensar o processo de ensino-aprendizagem de uma forma multidisciplinar, o que já é uma realidade, tem agora a oportunidade de se consolidar também de forma multipológica e multididática.

\section{REFERÊNCIAS}

ABED - Associação Brasileira de Educação a Distância. Censo EAD Brasil, 2016. Disponível em: http://abed.org.br/censoead2016/Censo_EAD_2016. Acesso em: 04 dez. 2017.

ABMES - Associação Brasileira de Mantenedoras de Ensino Superior. Portaria normativa № 11, de 20 de junho de 2017. Disponível em:

https://abmes.org.br/arquivos/legislacoes. Acesso em: 20 jan. 2018. 
ALVES, Lucineia. Educação a distância: conceitos e história no Brasil e no mundo, 2011. Disponível em:

http://www.abed.org.br/revistacientifica/Revista_PDF_Doc/2011/Artigo_07.pdf. Acesso em: 31 jan. 2018.

AZEVEDO, Wilson. Educação a distância na universidade do século XXI. 2000. Disponível em: http://www.aquifolium.com.br/educacional/artigos/spof2.html. Acesso em: 19 fev. 2018.

BARDIN, Laurence. Análise de Conteúdo. São Paulo: Edições 70, 2006.

BARDIN, Laurence. Análise de Conteúdo. Lisboa, Portugal; Edições 70, LDA, 2009.

BELLONI, Maria Luiza (2003). Educação a distância. 3ª ed. Campinas: Autores Associados, 2008.

BRASIL. Lei de Diretrizes e Bases da Educação, 20 de dezembro de 1996. Disponível em: http://www.planalto.gov.br/Ccivil_03/leis/L9394.htm. Acesso em: 15 jan. 2018.

BRASIL. Lei 10.172/01 em janeiro de 2001. Disponível em:

http://www.planalto.gov.br/ccivil_03/leis/leis_2001/l10172.htm. Acesso em: 20 jan. 2018.

BRASIL. Decreto № 5.622, de 19 de dezembro de 2005. Disponível em: http://portal.mec.gov.br/seed/arquivos/pdf/dec_. Acesso em: 15 jan. 2018.

BRASIL. Decreto no 6.096, de 24 de abril de 2007. Disponível em: http://www.planalto.gov.br/ccivil_03/_ato2007-2010/2007/decreto/d6096.htm. Acesso em: 20 jan. 2018.

COUTINHO, Clara Pereira; BOTTENTUIT JUNIOR, João Batista. Blog e Wiki: Os Futuros Professores e as Ferramentas da Web 2.0, 2007. Disponível em: https://repositorium.sdum.uminho.pt/bitstream/1822/7358/1. Acesso em: 20 fev. 2018.

DEMO, Pedro. Educação Hoje: Novas Tecnologias, Pressões e Oportunidades. São Paulo: Atlas, 2009.

FORNARI, Juliana Savoy. A Paideia: Cultura, Cibercultura e a Educação à Distância. Filosofia e Educação, Campinas, SP, v.10, n.1, p. 154-165, jan./abr. 2018 - ISSN 1984-9605.

GONÇALVES, Marilícia Brandão Mól. Relação espaço e tempo na prática pedagógica da educação a distância do IFMG - Campus Ouro Preto. Disponível em: http://www.fumec.br/revistas/sigc/article/view/4021/2519. Acesso: 11 mar. 2018.

INEP- Instituto Nacional de Estudos e Pesquisas Educacionais Anísio Teixeira Legislação e Documentos. Censo da Educação Superior de 2016. Disponível em: http://download.inep.gov.br/educacao_superior/censo_superior/documentos/2016/nota s_sobre_o_censo_da_educacao_superior_2016.pdf. Acesso em: 04 dez. 2017.

KENSKY, Vani Moreira. Educação e Internet no Brasil. Disponível em: http://www.pucrs.br/ciencias/viali/doutorado/ptic/textos/Kenski.pdf. Acesso em: 15 de jan. 2018.

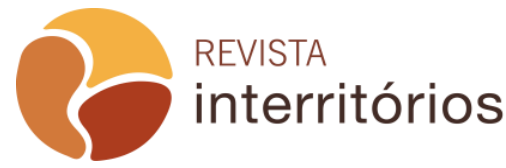


LANDIM, C. M. das M. P. F. Educação a distância: algumas considerações. Rio de Janeiro: Edição do Autor, 1997.

LEMGRUBER, Márcio Silveira. Educação a Distância: para além dos caixas eletrônicos. Disponível em:

http://portal.mec.gov.br/arquivos/conferencia/documentos/marcio_lemgruber. Acesso: 31 jan. 2018.

LICHESKI, Laís C.; FADEL, Luciane Maria. Acessibilidade digital. Revista Brasileira de Design da Informação, v.10, n.2, p. 104-122, 2013.

LITTO, FREDRIC M. As interfaces da EAD na educação brasileira. REVISTA USP, São Paulo, n. 100, p. 57-66.

LUCENA, Marisa. Comunidade Dinâmica para o aprendizado na internet. Revista Brasileira de Informática na Educação, n.2, 1998.

MAIA, Gabrielle. Bases Pedagógicas da EaD. Educação a Distância. Disponível em: https://eventos.set.edu.br/index.php/simeduc/article/viewFile/3355/1281. Acesso em: 03 maio 2018.

MIRANDA, Luísa Augusta Vara. Educação Online: Interação e Estilos de Aprendizagem de Alunos do Ensino Superior numa Plataforma Web. Tese de Doutorado em educação. Universidade do Minho, Braga, 2005.

MOODLEMOOT. Conferência dedicada aos usuários, desenvolvedores e administradores do MOODLE. 2014. Disponível em: https://www.moodlebrasil.org/. Acesso em: 20 mar. 2018.

MORAN, José. O que é educação a distância. Disponível em:

http://www2.eca.usp.br/moran/ wp-content/uploads/2013/12/dist.pdf. Acesso em 31 jan. 2018.

MORAN, José. O ensino superior a distância no Brasil. Disponível em: https://www.metodista.br/revistas/revistas-ims/index.php/EL/article/view/811/879. Acesso em: 11 mar. 2018.

MOTTA, Alexandre; GAVILON, Igor; Introdução à educação a distância e ambiente virtual de ensino - aprendizagem. Florianópolis: Publicações do IF-SC, 2010.

MUGNOL, Marcio. A Educação a Distância no Brasil: conceitos e fundamentos. Revista Diálogo Educacional. Pontifícia Universidade Católica do Paraná, Curitiba, v. 9, n. 27, p. 335-349, maio/ago. 2009, ISSN 1518-3483.

PEREIRA, Alice Theresinha Cybis; SCHMITTE, Valdenise; DIAS, Maria Regina Álvares C. Ambientes Virtuais de Aprendizagem. 2007.

PEREIRA, Larissa Dahmer; SOUZA, Andréa Cristina Viana de. Mercantilização do ensino superior brasileiro e o uso do EaD como estratégia expansionista. 2017. Disponível em: http://www.niepmarx.blog.br/MM2017/anais2017/MC30/mc301.pdf. Acesso em: 20 de fev. 2018. 
PIMENTEL, P. C. F. Impacto da plataforma Moodle nas escolas de Famalicão: um estudo de caso. Dissertação de mestrado. Universidade do Minho, Braga, 2009.

SANTOS, Edméa Oliveira dos. Ambientes Virtuais de Aprendizagem: Por autorias livre, Plurais e Gratuitas. Disponível em:

http://www.comunidadesvirtuais.pro.br/hipertexto. Acesso em: 26 fev. 2018.

SANTOS, Rui; JORGE, Idalina. Utilização da plataforma Moodle por docentes do ensino não superior: o caso da escola EB 2, 3 S. João de Deus. Agrupamento de Escolas nำ1 de Montemor-o-Novo, Portugal. Revista EFT: Educação, Formação \& Tecnologias. 6 (1), p.68-85, 2013.

SILVA, M. Sala de aula interativa. São Paulo: Edições Loyola, 2010.

TURBAN, E. ; KING, D. Comércio Eletrônico: Estratégia e Gestão. São Paulo: Pearson, 2004.

UNESCO. Relatório de Monitoramento Global de EPT. Paris: 2014. Disponível em: http://unesdoc.unesco.org/images/0022/002256/225654por.pdf. Acesso em: 20 de mar. 2018.

UNIVERSIA. Universa Brasil (2016). Educação à Distância é a que mais cresce no Brasil. Censo do MEC. Disponível em:

http://noticias.universia.com.br/destaque/noticia. Acesso em: 09 fev. 2018. 